\title{
Lyon 5e « Lugdunum »
}

Place François-Bertas

\section{Emmanuel Bernot}

\section{(2) OpenEdition}

12 Journals

Édition électronique

URL : http://journals.openedition.org/adlfi/6885

ISSN : 2114-0502

Éditeur

Ministère de la culture

Référence électronique

Emmanuel Bernot, « Lyon 5e « Lugdunum » », ADLFI. Archéologie de la France - Informations [En ligne], Rhône-Alpes, mis en ligne le 01 mars 2007, consulté le 03 mai 2019. URL : http:// journals.openedition.org/adlfi/6885

Ce document a été généré automatiquement le 3 mai 2019.

(c) Ministère de la Culture et de la Communication, CNRS 


\title{
Lyon 5e « Lugdunum »
}

\author{
Place François-Bertas
}

\section{Emmanuel Bernot}

Identifiant de l'opération archéologique : 229337

Date de l'opération : 2007 (EV)

1 Les fouilles réalisées dans le cadre de l'aménagement des abords de l'église Saint-Georges (construction d'un local de fontainerie) ont permis de mettre au jour quelques rares témoins d'une fréquentation du lieu au cours du III ${ }^{\mathrm{e}}$ siècle de notre ère.

2 L'occupation du site ne se confirme réellement que dix siècles plus tard, à partir du XIII s., avec la construction d'un imposant mur orienté nord-est - sud-ouest et d'un second en retour vers la rivière. Leur mise en place s'accompagne d'un remblaiement important afin de se préserver des caprices du cours d'eau. Ces vestiges correspondent à l'une des trois maisons bordant la Saône et figurées sur le plan scénographique de la ville réalisé vers 1550. Ces bâtiments, qui font partie des possessions de l'ordre de Saint-Jean-deJérusalem au moins depuis le milieu du XVe s., abritent la cure de Saint-Georges à la fin de ce même siècle. Durant la totalité du XVII ${ }^{e}$ s., leur rez-de-chaussée est loué à un teinturier qui y tient sa boutique et son atelier, dont l'un des fours a été découvert (Fig. ${ }^{\circ} 1$ : Vestiges d'un four d'atelier de teinturier en fonction au cours du XVII ${ }^{\mathrm{e}} \mathrm{s}$. ).

$3 \mathrm{Au}$ début du XVIII ${ }^{\mathrm{e}}$ s., les bâtiments de la cure sont détruits et, en 1758, une nouvelle maison curiale est édifiée sur ce même emplacement. Ses caves ont été partiellement mises au jour. Elles se composent d'un escalier débouchant du rez-de-chaussée depuis l'ouest et aboutissant à un large couloir orienté nord-est - sud-ouest. Ce couloir dessert, au nord, une vaste cave dont seule une petite partie est située dans l'emprise de la fouille. Cet espace a été partiellement fouillé à l'occasion d'un sondage réalisé en 1998. Au sud du couloir, se trouve une cave similaire, dont l'angle nord-ouest a également été mis au jour dans un autre sondage réalisé en 2006. Au $\mathrm{XIX}^{\mathrm{e}}$ s., une citerne y est aménagée ; elle est alimentée par une canalisation destinée à récupérer les eaux pluviales depuis la toiture. Enfin, depuis le couloir, deux portes donnent accès à des caves situées hors emprise, sous 
la partie orientale de la maison. Tous les sols de ces caves ont été abaissés au cours du XIX ${ }^{\mathrm{e}} \mathrm{s}$., supprimant ainsi tous les niveaux d'occupation antérieurs liés à la maison curiale.

\section{ANNEXES}

Fig. $n^{\circ} 1$ : Vestiges d'un four d'atelier de teinturier en fonction au cours du XVII e $s$.

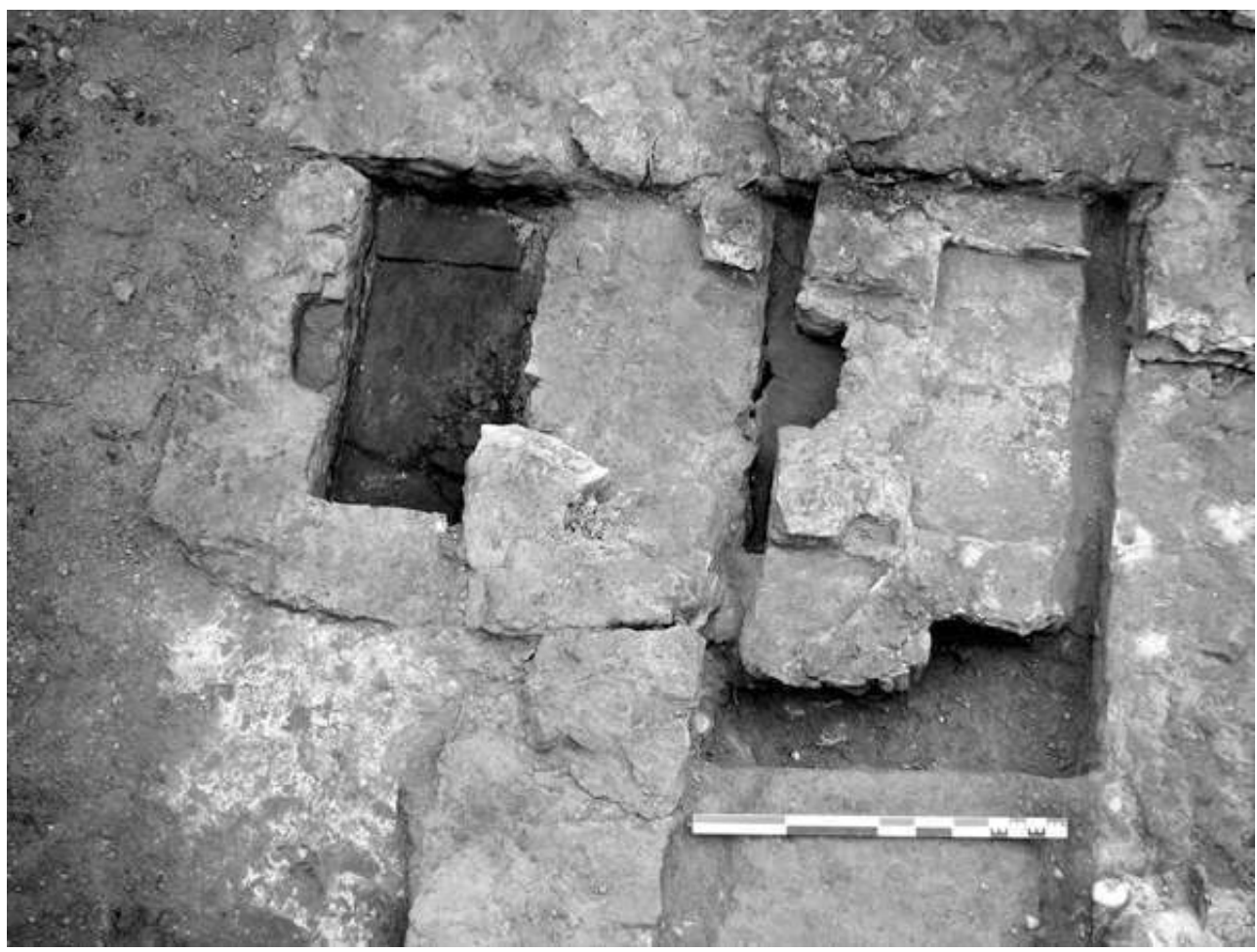

Auteur(s) : Bernot, Emmanuel. Crédits : ADLFI (2007)

INDEX

Index chronologique : Antiquité romaine, IIIe siècle apr. J.-C., Moyen Âge, Temps Modernes, XIIIe siècle apr. J.-C., XIXe siècle apr. J.-C., XVe siècle apr. J.-C., XVIIe siècle apr. J.-C.

Index géographique : Rhône-Alpes, Rhône (69), Lyon (69123)

operation Fouille d'évaluation (EV)

\section{AUTEURS}

EMMANUEL BERNOT

COL 